\title{
The new FDG brain revolution: the neurovascular unit and the default network
}

\author{
Stelvio Sestini • Antonio Castagnoli • Luigi Mansi
}

Published online: 22 December 2009

(C) Springer-Verlag 2009

"Our aim is, more than see new things, to see with new eyes what has already been seen"

Baruch Spinoza

\section{The first FDG brain revolution}

The first revolution was explosive. Using ${ }^{18} \mathrm{~F}$-fluorodeoxyglucose (FDG), it was possible to see and study the living brain in humans! Pioneers were top experts who provided different specialized expertise, but strictly cooperating between themselves [1]. Physicists, engineers and mathematicians were actively involved in producing the best hardware and software. The research on crystals, in identifying the most effective electronics, in defining accurate methods for attenuation and scatter correction and so on, was nevertheless limited by the relatively poor technology, with the main consideration being limited computer power. These developments stimulated a major interest in the brain. Satisfactory sensitivity and resolution, together with reliable solutions to the technical problems, were only achieved with dedicated cerebral PET scanners which had a field of view that permitted exclusive analysis of the brain.

Basic scientists had the possibility of realizing a scientific dream: the transfer of data on cerebral glucose metabolism acquired in animals by quantitative autoradiography to humans. Another issue in the original FDG PET

S. Sestini $(\bowtie) \cdot$ A. Castagnoli $\cdot$ L. Mansi

Department of Diagnostic Imaging, Nuclear Medicine Unit, Ospedale Misericordia e Dolce,

Prato, Italy

e-mail: ssestini@us14.toscana.it research was to consider mandatory absolute quantification. Thus arterial (or arterialized) sampling, to obtain data to be included in mathematical models, was routinely performed. However, because the equations included nonmeasurable parameters, the presence of a lumped constant affected absolute measurement in an individual [2-4]. PET teams included (and were directed by) clinical experts including not only nuclear physicians, but also other professionals such as neuroradiologists, neurologists and psychiatrists, who frequently cooperated with psychologists, anatomists and physiologists.

Because of the unsatisfactory spatial resolution and the negative influence of the partial volume effect, in presence of glucose uptake in the normal brain, only a low lesion/background ratio was achievable, except for hot spots, i.e. the presence of focal areas of increased uptake determined by physiological and/or pathological causes. Therefore, the use of FDG as a positive indicator was restricted in the first studies and in the search for hot spots, many studies involved physiological stimulation tests (closed/open eyes, auditory system, etc.) in normal subjects $[5,6]$. Similarly, major interest in pathological analysis was directed to the evaluation of brain tumours, starting from Warburg's hypothesis of higher FDG uptake in malignant lesions with respect to benign ones [7]. With further clinical experience, in the analysis of patients with epilepsy, a higher sensitivity was clearly demonstrated during the ictal phase, the focus being seen as a hot spot, with respect to the interictal period when the lesion was not easily detectable, being an area with a slightly reduced overall FDG uptake $[8,9]$. Discrepant results in epilepsy clearly demonstrate how, in the absence of a structural lesion evident on $\mathrm{CT}$, it is more difficult to search for a functional alteration when it corresponds to an area of decreased uptake (cold spot). 
As a consequence of the unsatisfactory lesion/background ratio and, partially, of the morphostructural background of many of the pioneers, the first studies of the detectability of cold lesions were therefore mainly directed to identify areas of decreased FDG uptake in territories where this was suspected a priori. For example, Di Chiro et al., recognizing the primacy of the use of FDG PET for brain tumours, stated that "cerebral cortical glucose utilization was often depressed in areas adjacent to or neurally connected to the tumor site" [7]. These authors enthusiastically participated in clinical research leading to the detection of cerebellar diaschisis, seen as an area of decreased glucose metabolism in patients affected by neurologically connected contralateral cerebral tumours [10]. In fact, as already demonstrated in 1914 by Von Monakov [11], this phenomenon indicates a functional alteration without morphostructural evidence, as determined by the loss of neurological connections caused by cerebral involvement by tumour. Conversely, Di Chiro did not immediately change his perception of Alzheimer's disease. The first studies by the team working with him at the National Institutes of Health indicated the disease to be a focal unilateral brain alteration, clinically related to the main symptoms [12]. When, contrary to the previous observations, Chase et al. demonstrated for the first time the typical bilateral posterior hypometabolic pattern, not connected to any of the previously known neurological models and without pathological evidence on CT, Di Chiro declined to be included in the first communication [13]; therefore he did not participate in the primacy of this pivotal observation, which was shared with Friedland and colleagues [14].

In almost 30 years since the first developments in the 1980, the role of FDG PET in the clinical study of brain diseases has been defined. At present, while there is no further potential for the use of FDG for stimulation tests and while there is still only a limited role for its use in the study of brain tumours, partially in competition with alternative PET radiotracers, the clinical use of FDG in dementia is increasing worldwide. This situation has been strongly supported by technological and methodological developments, mainly involving the use of highperformance scanners and statistical parametric analysis, which also allow reliable evaluation in the preclinical phase. But are a higher spatial resolution and a more statistically significant database the only new horizons for FDG in brain diseases?

\section{The new FDG brain revolution: FDG as a biomolecular tracer}

Advances in emission tomography techniques and a more refined understanding of neural signalling mechanisms in normal and pathological conditions have led to a deeper awareness of the potential of FDG and PET in investigating the functional anatomy of human brain function, in detecting metabolic changes at any point in this network in normal and pathological conditions, and in characterizing the timing of the appearance of such regional changes. Therefore, although other tracers can be considered for these purposes, the importance of in vivo measurement of the rate of regional glucose utilization in basic and clinical research into such devastating and widespread disorders as neurodegenerative diseases cannot be overstated $[15,16]$.

Starting from the knowledge that oxidation of glucose provides almost all of the energy needed by neurons to support brain activity [17, 18], during the last decades researchers have changed their traditional view that glucose is consumed exclusively by neurons and that glucose consumption directly reflects neural activity [19]. In this respect, the importance of astrocytes in glutamate-driven glucose metabolism and regulation has been highlighted [20]. Several experiments have shown that this type of glial cell in the central nervous system is closed to glutamatergic synapses and responds to neural activity by consuming more glucose and producing more lactate [21]. In parallel it has been shown that neurons preferentially oxidize lactate present in the extracellular space rather than glucose to meet their energy needs [22, 23]. Besides the pivotal role in the regulation of glucose metabolism for synaptic transmission, emerging evidence implicates astrocytes as one of the key players coordinating the vascular response to neuronal activation. By acting in a coordinated manner, astrocytes might integrate neuronal activity over large spatial domains and thereby coordinate vasodilatation within microcirculatory units [24]. Thus, evaluation of brain using FDG is likely to reflect a very different and complex scenario from that originally proposed, which is not merely limited to neural activity but involves the activity of the entire neurovascular unit and the multifunctional role of astrocytes which subserve the moment-to-moment and spatialto-spatial changes in synaptic transmission and subsequent dynamic changes in regional cerebral blood flow [23].

With this knowledge, researchers have devoted much effort to answering the important question of how dynamic signalling within the neurovascular unit is integrated with other pathways in health and disease during rest [23]. Moving from the observation that cerebral metabolism during a quiet rest state is as vigorous as that when individuals solve externally administered matching problems [25], brain imaging research in recent years has completely changed the traditional view that FDG PET brain images at rest poorly reflect a homogeneous distribution of low levels of glucose consumption in cortical and subcortical regions. In this respect, novel insights have indicated the presence of multiple interacting systems called the "default network" which is preferentially active 
at rest when individuals are engaged in internally focused tasks including autobiographical memory retrieval, visualizing the future, and conceiving the perspectives of others [26]. Although the functional and anatomical implications of such a multiple interacting system in healthy subjects are still under discussion, converging lines of evidence suggest that the default network could also be relevant for understanding several diseases including mental disorders and Alzheimer's disease [27]. In this respect, it has been emphasized that the potential of FDG PET for investigating the changes in regional synaptic activity of the default network during disease can be considered only the last step on a long road extending back to the earliest studies of the relationship between the site of neurological dysfunction and the neural basis of the functional imaging signal with FDG [28-30].

Indeed, the role of functional imaging with FDG PET would not be so important if the results of two decades of investigation into the molecular genetics and pathophysiology of brain disorders had not clearly demonstrated that degeneration occurs preferentially at the synaptic level and involves dysfunction in mitochondrial energy metabolism [31-33]. For this reason, this technique is nowadays considered the most appropriate approach to track local energetic transformation in the living human brain [34]. Since functional imaging signals are closely linked to the activity of glutamatergic synapses, any dysfunctioning of the dialogue between glutamatergic neurons and astrocytes could lead to altered functional brain images [35]. As previously reported [32], the net changes in regional glucose metabolism can be investigated in the primary sites of neuronal degeneration as well as in the secondary widespread brain regions spatially removed from the neurochemical locus of the pathology. While measurements at the primary sites of degeneration over time can provide an insight into the natural history of disease, the study of functional alterations in brain regions distant from the primary locus of the pathology may be relevant to the domino-like effect of disease and the emerging beneficial role of neural compensatory mechanisms outside the primary sites of neurodegeneration. Beside, the relationship between brain regions showing changes in neural activity and the clinical status of the patients during scanning can be investigated to reveal the possible circuits involved in the genesis of the cardinal symptoms of brain disorders, to drive drug development and to follow the effects of therapies on cerebral regions with abnormal metabolism. In this respect, as previously highlighted [36], as preventive and disease-modifying treatments are developed, early detection of accurately diagnosed altered processes facilitated by the use of FDG PET has the potential to substantially impact on the enormous human toll exacted by these diseases.

\section{Final remarks}

Do we have the instruments and the knowledge to implement or modify our methodology in studying FDG as a biomolecular tracer? The technological developments since the 1980s have led to an extraordinary improvement in both the sensitivity and spatial resolution of PET scanners. Today, because of new technologies and of the exponential increase in computer power, it is possible to perform fast dynamic studies, in the order of seconds, with a resolution reaching values close to $2 \mathrm{~mm}$ using animal PET. Therefore, a first frontier may be to use animal models to acquire in vivo quantitative data, obtained using equations based on measurable experimental parameters. In this direction, a major improvement has resulted from the availability of high-performance scanners and microfluidic devices, which permit blood sampling in small animals, as a prerequisite to absolute quantitative measurements, both at rest and under stimulation, in normal and pathological conditions [37].

With the neurovascular unit, including various cells and compartments, as a research target, new interest could be stimulated not only in new radiotracers as neurotransmitters, but also in earlier studies on the quantitative evaluation of parameters such as the cerebral haematocrit or the permeability of the blood-brain barrier. It is interesting to note that some of these studies were performed using generator-produced radionuclides including ${ }^{68} \mathrm{Ga},{ }^{82} \mathrm{Rb}$ and ${ }^{62} \mathrm{Cu}[38-41]$.

Finally, if we want to understand FDG as a biomolecular tracer, we need to start to work, as in the pioneering phase, with the fullest cooperation between different specialized areas of expertise, including basic scientists. In this direction, the involvement in the field, together with many emerging and already consolidated scientific teams, of personalities such as Louis Sokoloff and Michael Phelps $[37,42]$ is a significant stimulus to a continuous link between 30 years of research on FDG and the future.

\section{References}

1. Wagner HN Jr, Knight N. A personal history of nuclear medicine. Springer Verlag; 2006.

2. Sokoloff L. [1-14C]-2-deoxy-d-glucose-method for measuring local cerebral glucose utilization. Mathematical analysis and determination of the "lumped" constants. Neurosci Res Program Bull 1976;14:466-8.

3. Reivich M, Kuhl D, Wolf A, Grenberg J, Phelps M, Ido T, et al. The [F-18]fluorodeoxyglucose method for the measurement of local cerebral glucose utilization in man. Circ Res 1979;44:127-37.

4. Reivich M, Alavi A, Greenberg J, Wolf A. [F-18]fluorodeoxyglucose method for measuring local cerebral glucose metabolism in man: technique and results. Prog Nucl Med 1981;7:138-48. 
5. Grenberg J, Reivich M, Alavi A, Hand P, Rosenquist A, Rintelmann W, et al. Metabolic mapping of functional activity in human subjects with the [F-18]fluorodeoxyglucose technique. Science 1981;212:678-80.

6. Phelps ME, Mazziotta JC, Huang SC. Study of cerebral function with positron computed tomography. J Cereb Blood Flow Metab 1982;2:113-62.

7. Di Chiro G, De La Paz RL, Brooks RA, Sokoloff L, Kornblith PL, Smith BH, et al. Glucose utilization of cerebral gliomas measured by [F-18]fluorodeoxyglucose and positron emission tomography. Neurology. 1982;32:1323-9.

8. Engel J Jr, Kuhl DE, Phelps ME. Pattern of human local cerebral glucose metabolism during epileptic seizures. Science 1982;218: 64-6.

9. Theodore WH, Newmark ME, Sato S, Brooks R, Patronas N, De La Paz R, et al. [18F]fluorodeoxyglucose positron emission tomography in refractory complex partial seizures. Ann Neurol 1983;14(4):429-37.

10. Patronas NJ, Di Chiro G, Smith BH, De La Paz R, Brooks RA, Milam HL, et al. Depressed cerebellar glucose metabolism in supratentorial brain tumors. Brain Res 1984;291:93-101.

11. von Monakov C. Lokalisation im Gehirn und funktionelle störungen induziert durch kortikale läsionen. Wiesbaden: JF Bergmann; 1914.

12. Foster NL, Chase TN, Fedio P, Patronas NJ, Brooks RA, Di Chiro G. Alzheimer's disease: focal cortical changes shown by positron emission tomography. Neurology 1983;33:961-5.

13. Chase TN, Foster NL, Mansi L. Alzheimer's disease and the parietal lobe. Lancet 1983;2:225.

14. Friedland RP, Budinger TF, Ganz E, Yano Y, Mathis CA, Koss B, et al. Regional cerebral metabolic alterations in dementia of the Alzheimer type: positron emission tomography with [F-18] fluorodeoxyglucose. J Comput Assist Tomogr 1983;7:590-8.

15. Silverman DHS. Evaluating pathology in the brain with nuclear medicine. Semin Nucl Med 2008;38(4):225-6.

16. Herholz K, Herscovitch P, Heiss WD. Imaging brain function. In: Herholz K, Herscovitch P, Heiss WD, editors. NeuroPET: positron emission tomography in neuroscience and clinical neurology, vol 3. New York: Springer-Verlag; 2004. p. 143-85.

17. Sokoloff L, Reivich M, Kennedy C, Des Rosiers MH, Patlak CS, Pettigrew KD, et al. The [14C]deoxyglucose method for the measurement of local cerebral glucose utilization: theory, procedure, and normal values in the conscious and anesthetized albino rat. J Neurochem 1977;28:897-916.

18. Sokoloff L. Energetics of functional activation in neural tissues. Neurochem Res 1999;24:321-9.

19. Pellerin L, Magistretti PJ. Let there be (NADH) light. Science 2004;305:50-2.

20. Attwell D, Laughlin SB. An energy budget for signaling in the grey matter of the brain. J Cereb Blood Flow Metab 2001;21: 1133-45.

21. Pellerin L, Magistretti PJ. Glutamate uptake into astrocytes stimulates aerobic glycolysis: a mechanism coupling neuronal activity to glucose utilization. Proc Natl Acad Sci U S A 1994;91:10625-9.

22. Sibson NR, Dhankhar A, Mason GF, Rothman DL, Behar KL, Shulman RG. Stoichiometric coupling of brain glucose metabolism and glutamatergic neuronal activity. Proc Natl Acad Sci U S A 1998;95:316-21.
23. Kasischke KA, Vishwasrao HD, Fisher PJ, Zipfel WR, Webb WW. Neural activity triggers neuronal oxidative metabolism followed by astrocytes glycolysis. Science 2004;305:99-103.

24. Koehler RC, Roman RJ, Harder DR. Astrocytes and the regulation of cerebral blood flow. Trends Neurosci 2009;32(3):160-9.

25. Sokoloff L, Mangold R, Weschsler RL, Kennedy C, Kety SS. The effect on mental arithmetic on cerebral circulation and metabolism. J Clin Invest 1955;34:1101-8.

26. Buckner RL, Andrews-Hanna JR, Schacter DL. The brain's default network. Anatomy, function and relevance to disease. Ann N Y Acad Sci 2008;1124:1-38.

27. Garrity AG, Pearson GD, McKierman K, Lloyd D, Kiehl K, Calhoun V. Aberrant "default mode" functional connectivity in schizophrenia. Am J Psychiatry 2007;164(3):450-8.

28. Shulman RG, Rothman DL, Behar KL, Hyder F. Energetic basis of brain activity: implications for neuroimaging. Trends Neurosci 2004;27:489-95.

29. Barros LF, Porras OH, Bittner CX. Why glucose transport in the brain matters for PET. Trends Neurosci 2005;28:117-9.

30. Attwell D, Iadecola C. The neural basis of functional brain imaging signals. Trends Neurosci 2002;25:621-5.

31. Schon EA, Manfredi G. Neuronal degeneration and mitochondrial dysfunction. J Clin Invest 2003;111:303-12.

32. Mattson PM, Magnus T. Ageing and neuronal vulnerability. Nature 2006;7:278-94.

33. Fukui H, Morales CT. The mitochondrial impairment, oxidative stress and neurodegeneration connection: reality or just an attractive hypothesis? Trends Neurosci 2008;31(5):251-6.

34. Sestini $\mathrm{S}$. The neural basis of functional neuroimaging signal with positron and single-photon emission tomography. Cell Mol Life Sci 2007;64:1778-84.

35. Weng X, Ding YS, Wolkow ND. Imaging the functioning human brain. Proc Natl Acad Sci U S A 1999;96:11073-4.

36. Silverman DHS, Mosconi L, Ercoli L, Chen W, Small GW. Positron emission tomography scans obtained for the evaluation of cognitive dysfunction. Semin Nucl Med 2008;38(4):251-61.

37. Yu AS, Lin HD, Huang SC, Phelps ME, Wu HM. Quantification of cerebral glucose metabolic rate in mice using 18F-FDG and small-animal PET. J Nucl Med 2009;50:966-73.

38. Lammerstma AA, Brooks DJ, Beaney RP, Turton DR, Kensett MJ, Heather JD, et al. In vivo measurement of regional cerebral haematocrit using positron emission tomography. J Cereb Blood Flow Metab 1984;4:317-22.

39. Okazawa H, Yonekura Y, Fujibayashi Y, Yamauchi H, Ishizu K, Nishizawa S, et al. Measurement of regional cerebral plasma pool and haematocrit with Copper-62 labeled HSA-DTS. J Nucl Med 1996;37:1080-5.

40. Brooks DJ, Beaney RP, Lammerstma AA, Leenders KL, Horlock PL, Kensett MJ, et al. Quantitative measurement of blood brain barrier permeability using rubidium-82 and positron emission tomography. J Cereb Blood Flow Metab 1984;4:535-45.

41. Iannotti F, Fieschi C, Alfano B, Picozzi P, Mansi L, Pozzilli C, et al. Simplified non invasive PET measurement of blood brain barrier permeability. J Comput Assist Tomogr 1987;11: $390-7$.

42. Sokoloff L. The physiological and biochemical basis of functional brain imaging. Cogn Neurodyn 2008;2:1-5. 